\title{
Sodium dithionite-enhanced quality of radix scutellariae through modification of secondary metabolism
}

\author{
Guo Huimin, Fu Xiaoying, Du Hongwei, Cong Wei, Meng Xiangcai \\ Department of Pharmacognosy, Heilongjiang University of Chinese Medicine, Harbin 150040, China
}

\begin{abstract}
Introduction: The quality of radix scutellariae is particularly associated with environmental stresses, but detailed mechanisms remained unclear. Plant under unfavorable situation generates redundant reactive oxygen species (ROS), and ROS can modify the secondary metabolism. The varied quality of radix scutellariae could be explained by ROS. Materials and Methods: $0.004,0.4$, and $40 \mu \mathrm{mol} / \mathrm{L}$ of sodium dithionite $\left(\mathrm{Na}_{2} \mathrm{~S}_{2} \mathrm{O}_{4}\right)$, a material producing ROS, were applied to Scutellaria baicalensis to mimic unfavorable situation. The relationship between ROS, antioxidant enzymes activity, and secondary metabolite was investigated. Results: ROS level fails to rise due to both the antioxidase and the secondary metabolites. The activities of both superoxide dismutase and catalase in the roots of $S$. baicalensis showed a moderately improvement, meanwhile the phenylalanine ammonia lyase was strongly expressed, and the biosynthesis of flavonoids was heavily elevated. Although the glycosides such as baicalin and wogonoside changed little, the aglycones with the highest effective, such as baicalein and wogonin, were increased by approximately $50 \%-100 \%$. Conclusion: This is very valuable in insight into the stress physiology and provides a strong tool to enhance the quality of radix scutellariae.
\end{abstract}

Key words: Antioxidase, flavonoids, reactive oxygen species, Scutellaria baicalensis, secondary metabolite

\section{INTRODUCTION}

The root of Scutellaria baicalensis Georgi is a widely popular herbal medicine in Asia; its main active constituents are flavonoids include baicalin, wogonoside, baicalein, and wogonin. ${ }^{[1]}$ The flavonoids have been shown to be correlated to circumstance, its content changes between various conditions, even has a very fine daily periodicity oscillation. ${ }^{[2]}$

The use of herbal medicine has a history of several thousand years. About 1200 years ago, it was realized that the qualities varied according to producing regions with specific environmental stress as Tridax procumbens does. ${ }^{[3]}$ The Chinese Government promulgated "Good Agriculture Practice for Chinese Crude Drugs" to control various factors affecting the production quality of medicinal plant materials and further to ensure that traditional

Address for correspondence:

Prof. Meng Xiangcai,

School of Pharmaceutical Sciences, Heilongjiang University of

Chinese Medicine, 24, Heping Road, Harbin, 150040, China.

E-mail: mengxiangcai000@163.com

\begin{tabular}{|l|l|}
\hline \multicolumn{2}{|c|}{ Access this article online } \\
\hline Quick Response Code: & Website: \\
\hline & www.jpionline.org \\
\cline { 2 - 2 } & DOI: \\
\hline
\end{tabular}

Chinese medicine herbs are authentic, safe, effective, and consistent in quality. ${ }^{[4]}$ Besides China, many countries have taken a series of standardized measures concerning quality control of the production of raw materials for natural medicines, but all these pay attention to production procedure, not to specific active ingredient relevant to the effect. ${ }^{[5]}$ Research has so far proved that intense light and drought are responsible for the quality of radix scutellariae, but detailed mechanisms remained unclear. ${ }^{[2,6]}$

The plant cannot search for suitable circumstance by moving and therefore often face various adversities such as intense light, drought which do great harm to the plant. The nature of damage derives from the production of reactive oxygen species (ROS) ${ }^{[7]}$ To avoid or alleviate the damage, an exceptional metabolic mechanism, secondary metabolism, was created and hence the environmental stress, ROS, and secondary metabolism are intimately connected together. There are many

This is an open access article distributed under the terms of the Creative Commons Attribution-NonCommercial-ShareAlike 3.0 License, which allows others to remix, tweak, and build upon the work non-commercially, as long as the author is credited and the new creations are licensed under the identical terms.

For reprints contact: reprints@medknow.com

How to cite this article: Huimin G, Xiaoying $F$, Hongwei D, Wei C, Xiangcai M. Sodium dithionite-enhanced quality of radix scutellariae through modification of secondary metabolism. Int $\mathrm{J}$ Pharma Investig 2016;6:225-30. 
types of ROS, the ROS first generated is $\mathrm{O}_{2}{ }^{-}$in plant, then it is dismutated to $\mathrm{H}_{2} \mathrm{O}_{2}$ by superoxide dismutase (SOD). ${ }^{[7]}$ Sodium dithionite $\left(\mathrm{Na}_{2} \mathrm{~S}_{2} \mathrm{O}_{4}\right)$ is a substance which can generates $\mathrm{O}_{2}{ }^{-}$, it has the potential to mimic natural biological process and lead to the increased the production of secondary metabolites. The secondary metabolites of plant possess various pharmacological activities, usually are basic to treating various disease. ${ }^{[8]}$ Thus, it is probable that $\mathrm{Na}_{2} \mathrm{~S}_{2} \mathrm{O}_{4}$ be applied to enhance the quality of radix scutellariae.

\section{MATERIALS AND METHODS}

\section{Plant material}

S. baicalensis was used as target, identified by Prof. Meng Xiangcai, cultivated for 2 years, at the medicinal garden of the Heilong University of Chinese Medicine. It was divided equally into three parts on September 20, 2015, each parts were saturated with $\mathrm{Na}_{2} \mathrm{~S}_{2} \mathrm{O}_{4}$ of $0.004,0.4$, and $40 \mu \mathrm{mol} / \mathrm{L}$ at the 0 and $1^{\text {st }}$ day separately. The fresh roots of 10 individual plants were collected separately at the $0 \sim 4$ day, discarded xylem. $1.0 \mathrm{~g}$ sample comprising approximately $0.1 \mathrm{~g}$ of every plant was refrigerated at -80 for determination of $\mathrm{H}_{2} \mathrm{O}_{2}$. Similarly, $1.0 \mathrm{~g} \times 3$ samples were used for SOD, catalase (CAT), and polyphenol oxidase (PPO), $0.1 \mathrm{~g}$ for phenylalanine ammonia lyase (PAL) gene expression. The rest of fresh roots was dried at 55, then pulverized for determination of baicalin, wogonoside, baicalein, and wogonin. The above-specified samples were three replications.

\section{Determination of $\mathrm{H}_{2} \mathrm{O}_{2}$}

$\mathrm{H}_{2} \mathrm{O}_{2}$ were determinated with Plant $\mathrm{H}_{2} \mathrm{O}_{2}$ ELISA Kit (Purchased from Shanghai Yu Ping Biotechnology Limited Company, Made in the USA).

\section{Determination of antioxidase activities}

SOD activity (U), assayed based on the reduction of Nitroblue tetrazolium (NBT), was defined as the activity of enzyme that caused $50 \%$ of inhibition of NBT reduction. ${ }^{[9]}$ CAT activity, monitoring the decrease of $\mathrm{H}_{2} \mathrm{O}_{2}$ at $240 \mathrm{~nm}$ for $1 \mathrm{~min}$ at $25^{\circ} \mathrm{C}$, was calculated as the activity of enzyme that caused a reduction in absorbance at $240 \mathrm{~nm}$ of $0.01 / \mathrm{min}^{[10]}$

\section{Determination of phenylalanine ammonia lyase gene expression}

Targeted RNAs were extracted with the plant polyphenols polysaccharide kit (ABigen Corporation, Beijing, China). Reverse transcription was performed using the HiFi-MMLV cDNA first-strand synthesis kit. Real-time polymerase chain reaction (PCR) was carried out to detect gene expression. The target PAL fragment of $S$. baicalensis was $139 \mathrm{bp}$ in length. The forward and reverse primers were 5'-TGACCTCGTGCCCCTGTCCTAC-3' and 5'-CAGCTCGAAGAACCCTCCACTA ACT-3', respectively. The reaction system contained $10 \mu \mathrm{l} \times 2$ Ultra SYBR mixture, $0.4 \mu \mathrm{l}(10 \mu \mathrm{M}$ forward primer, $0.4 \mu \mathrm{l}(10 \mu \mathrm{M})$ reverse primer, $2 \mu \mathrm{l}$ template, and $6.8 \mu \mathrm{ldH_{2 }}$ O. The program of real-time PCR was as follows: $95^{\circ} \mathrm{C}$ for $10 \mathrm{~min}$, followed by 45 cycles of $95^{\circ} \mathrm{C}$ for $15 \mathrm{~s}$, and $60^{\circ} \mathrm{C}$ for $60 \mathrm{~s}$. ABI 7500 Applied Biosystems (American) was used for real-time PCR, and the $2^{-\triangle \Delta C T}$ method was used for data analysis.

Determination of baicalin, baicalein, wogonoside, and wogonin

$0.25 \mathrm{~g}$ of the root power $(\mathrm{d}<0.1 \mathrm{~mm})$ was put in a $25 \mathrm{ml}$ volumetric flask, then $70 \%$ methanol was added to extract the total compounds under ultrasonic condition for $30 \mathrm{~min}$; finally, the supernatant was filtered with a $0.22 \mu \mathrm{M}$ microporous filter for ultra performance liquid chromatography analysis.

The experimental samples were analyzed by water ACQUITY high-performance liquid chromatography. The trial samples are based on a BEH C18 column $(2.1 \mathrm{~mm} \times 50 \mathrm{~mm}, 1.7 \mu \mathrm{m})$. The mobile phases were composed of (A) acetonitrile with $0.1 \%$ formic acid (B) $\mathrm{H}_{2} \mathrm{O}$ with $0.1 \%$ formic acid. The gradient program as initial $25 \% \mathrm{~A}$ for $5 \sim 15 \mathrm{~min}$, and $25 \% \mathrm{~A} \rightarrow 54 \% \mathrm{~A}$ between 15 and $22 \mathrm{~min}$, then kept $54 \%$ A from 22 to $23 \mathrm{~min}, 54 \%$ $\mathrm{A} \rightarrow 25 \% \mathrm{~A}$ for $23 \sim 25 \mathrm{~min}$, and $25 \% \mathrm{~A}$. The flow rate was set at $1 \mathrm{ml} / \mathrm{min}$, and the column temperature was set at $30^{\circ} \mathrm{C}$. The detection wavelengths of baicalin, wogonoside, baicalein, and wogonin were $277,279,274$, and $275 \mathrm{~nm}$, respectively.

\section{Statistical analysis}

All the experimental data are expressed as mean values \pm standard deviation.

\section{RESULTS}

S. baicalensis were treated with $0.004,0.4$, and $40 \mu \mathrm{mol} / \mathrm{L}$ of $\mathrm{Na}_{2} \mathrm{~S}_{2} \mathrm{O}_{4}, \mathrm{H}_{2} \mathrm{O}_{2}$ contents in roots reduced by approximately $50 \%$ at the $1^{\text {st }}$ day, from 21 to $11 \mu \mathrm{mol} / \mathrm{ng}$, then gradually increased. The various dosage of $\mathrm{Na}_{2} \mathrm{~S}_{2} \mathrm{O}_{4}$ exhibited similar effect [Figure 1].

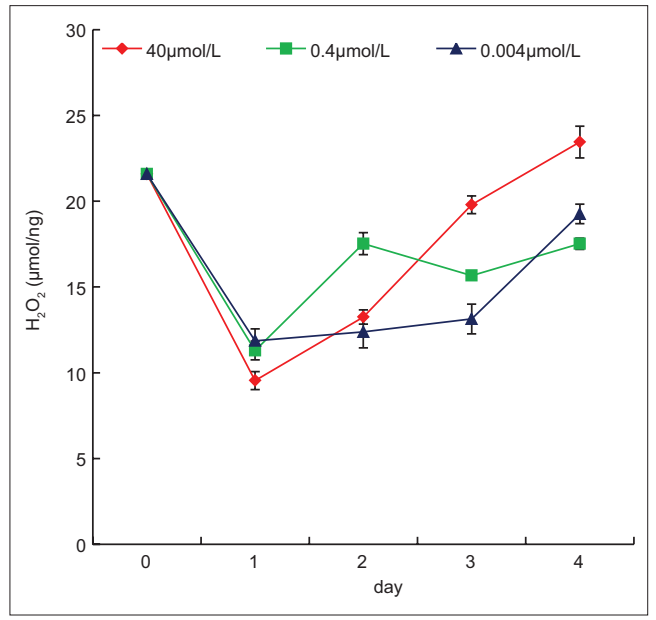

Figure 1: $\mathrm{H}_{2} \mathrm{O}_{2}$ contents in the roots of Scutellaria baicalensis. $\mathrm{H}_{2} \mathrm{O}_{2}$ contents reduced by approximately $50 \%$ at the $1^{\text {st }}$ day after treated, then gradually increased, indicating that redundant reactive oxygen species may be swiftly eliminated by either antioxidases or flavonoids 

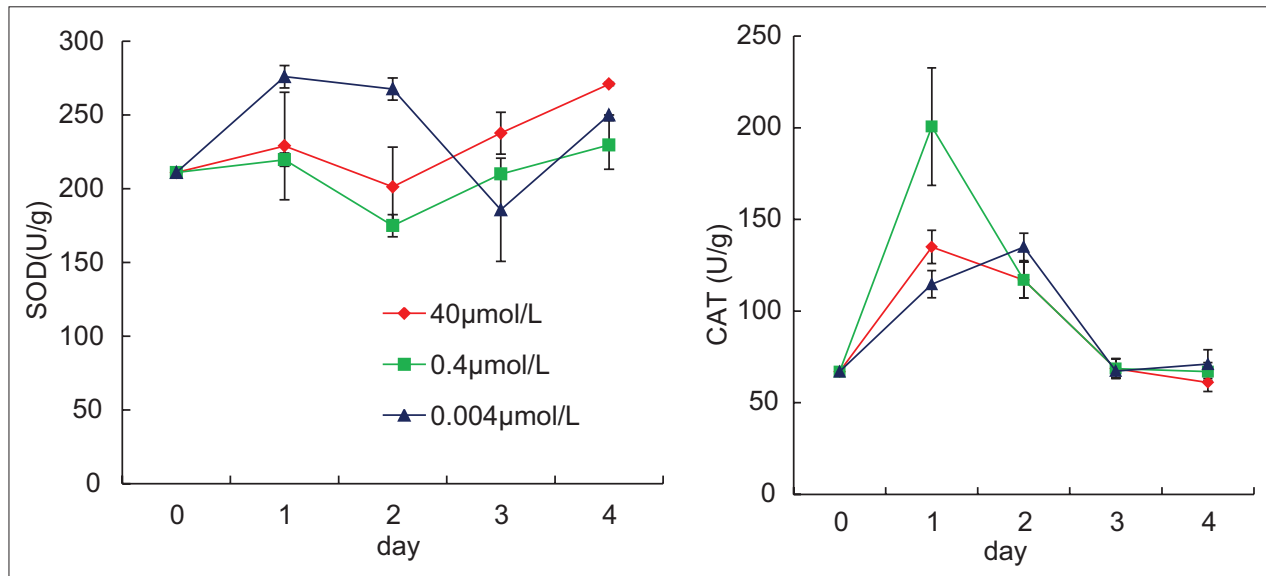

Figure 2: Activities of antioxidases in the roots of Scutellaria baicalensis. Superoxide dismutase activities changed little for the $0.004-0.4 \mu \mathrm{mol} / \mathrm{L}$, slightly for the $40 \mu \mathrm{mol} / \mathrm{L}$. Catalase activities were raised at the $1^{\text {st }}$ day, then gradually decreased. The antioxidases maybe play a role for eliminating reactive oxygen species.

SOD activities changed little for the $0.004-0.4 \mu \mathrm{mol} / \mathrm{L}$ of $\mathrm{Na}_{2} \mathrm{~S}_{2} \mathrm{O}_{4}$, slightly increased for the $40 \mu \mathrm{mol} / \mathrm{L}$. All CAT activities were raised at the $1^{\text {st }}$ day, then gradually decreased, which exhibited a tendency to be running counter to the $\mathrm{H}_{2} \mathrm{O}_{2}$ [Figure 2] .

The application of $\mathrm{Na}_{2} \mathrm{~S}_{2} \mathrm{O}_{4}$ increased PAL gene expression slightly for the $0.004 \mu \mathrm{mol} / \mathrm{L}$, remarkably for the 0.4 and the 40 $\mu \mathrm{mol} / \mathrm{L}$, furthermore last a long time [Figure 3].

The effects of $\mathrm{Na}_{2} \mathrm{~S}_{2} \mathrm{O}_{4}$ on flavonoids may be classified into two sets: flavone glycosides and aglucones. The glycosides changed little at different stages, but the aglucones were remarkably elevated at the $1^{\text {st }}$ day, then decreased. The baicalein increased from $0.1 \%$ to $0.28 \%$, the wogonin from $0.045 \%$ to $0.09 \%$ [Figure 4]. Initially, PPO activities were raised, then, gradually decreased [Figure 5]. It accords with that of aglucon.

Except for the PAL, above all physiological parameters have a tendency to recover its original state.

\section{DISCUSSION}

$\mathrm{H}_{2} \mathrm{O}_{2}$ contents in roots of Scutellaria baicalensis plants treated with sodium dithionite

The ROS first generated in plant is $\mathrm{O}_{2}{ }^{-}$. It is easily dismutated to relatively stable and membrane-permeable $\mathrm{H}_{2} \mathrm{O}_{2}$ either nonenzymatically or by SOD catalyzed the reaction, then $\mathrm{H}_{2} \mathrm{O}_{2}$ is converted to innoxious $\mathrm{H}_{2} \mathrm{O}$ by CAT, guaiacol peroxidase (POD), or ascorbate peroxidase (APX), and by this way, much of severe damage can be relieved. ${ }^{[7]}$ As a logical consequence, $\mathrm{Na}_{2} \mathrm{~S}_{2} \mathrm{O}_{4}$ must lead to excess production of $\mathrm{H}_{2} \mathrm{O}_{2}$. However, contrary to the anticipation, the $\mathrm{H}_{2} \mathrm{O}_{2}$ contents decreased by approximately $50 \%$ at the $1^{\text {st }}$ day after $0.004-40 \mu \mathrm{mol} / \mathrm{L} \mathrm{Na}_{2} \mathrm{~S}_{2} \mathrm{O}_{4}$ treated, then a gradual increase started [Figure 1]. Maybe it is because that a quick efficient elimination exists for $\mathrm{H}_{2} \mathrm{O}_{2}$.

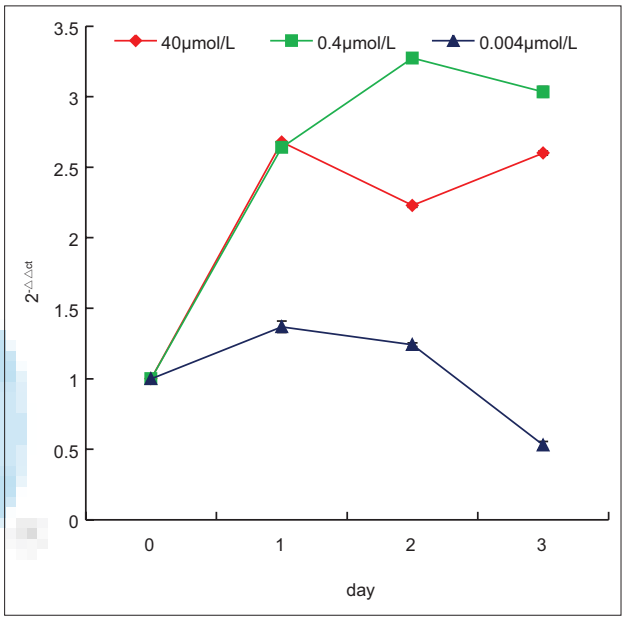

Figure 3: The expression of phenylalanine ammonia lyase in the roots of Scutellaria baicalensis. The application of sodium dithionite increased phenylalanine ammonia lyase gene expression slightly for the 0.004 $\mu \mathrm{mol} / \mathrm{L}$, remarkably for the 0.4 and the $40 \mu \mathrm{mol} / \mathrm{L}$, and led to enhanced biosynthesis of flavonoids

Activities of superoxide dismutase and catalase in roots of Scutellaria baicalensis plants-treated sodium dithionite

The antioxidant enzymes are widely found in living creature, either plant or animal. The enzymic components of the antioxidative defense system include SOD, CAT, and APX and so on. SOD is a major antioxidant enzyme, increased activity of SOD is often correlated with increased tolerance of the plant against environmental stresses. ${ }^{[7]}$ There are many antioxidant constituents, such as CAT, POD, AsA - GSH cycle, and APX, responsible for quenching $\mathrm{H}_{2} \mathrm{O}_{2}$. Among them, CATs are unique as they do not require cellular reducing equivalent, have a very fast turnover rate and thus are critical for maintaining the redox balance during the oxidative stress. ${ }^{[1]}$ Therefore, cell damage is subject to inhibition by both SOD and CAT. ${ }^{[7]}$ At the $1^{\text {st }}$ day after the $S$. baicalensis plants were treated with $\mathrm{Na}_{2} \mathrm{~S}_{2} \mathrm{O}_{4}$, the activities of both SOD and CAT in roots had 


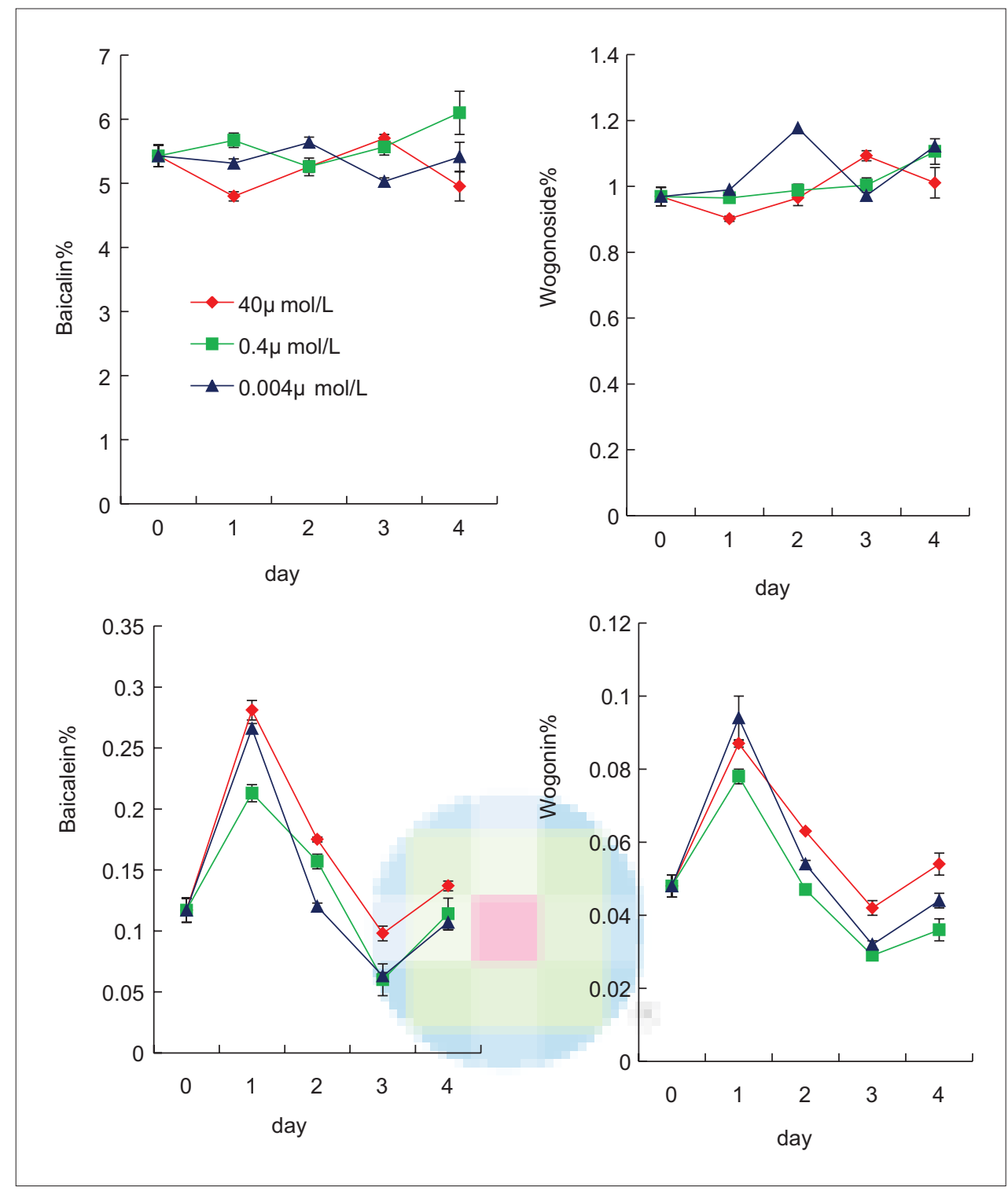

Figure 4: Biosynthesis of flavonoids in the roots of Scutellaria baicalensis. The glycosides with less activitie changed little at different stages, but the aglucones with more activities were remarkably elevated at the $1^{\text {st }}$ day, then decreased to prevent reactive oxygen species reducing too much

grown somewhat [Figure 2], which presented the same effects as many stress conditions did. Increased activities of both SOD and CAT contributed to abating cell damage, which indicated that antioxidases maybe play a role for eliminating ROS. Because increase of both SOD and CAT, especially the SOD, change a little, it seems impossible to result in major changes in $\mathrm{H}_{2} \mathrm{O}_{2}$ content. Here, we must mention that the least increased SOD activities of $0.4-40 \mu \mathrm{mol} / \mathrm{L} \mathrm{Na}_{2} \mathrm{~S}_{2} \mathrm{O}_{4}$ may be due to the heavy use of $\mathrm{Na}_{2} \mathrm{~S}_{2} \mathrm{O}_{4}$.

Biosynthesis of flavonoids in roots of Scutellaria baicalensis plants treated with sodium dithionite

ROS have double effects. At high concentration ROS causes damage to biomolecules, whereas at moderate concentration function as the second messenger in intracellular signaling cascades that mediate several responses in plant cells. ${ }^{[7]} \mathrm{O}_{2}{ }^{-} / \mathrm{H}_{2} \mathrm{O}_{2}$ generated in chloroplast have been proved to be responsible for triggering signaling pathways that ultimately induce changes in gene expression. ${ }^{[12]}$ In this study, the expression of PAL, a rate-limited enzyme responsible for the synthesis of flavonoids, was markedly upregulated [Figure 3], led to increased production of baicalin, wogonoside, baicalein, and wogonin [Figure 4]. Flavonoids play a crucial role in protecting cells from oxidative damage, they not only directly involve in quenching ROS, but also chelate transition metal ion $\mathrm{Fe}^{2+}$ to reduce Fenton reaction. ${ }^{[13,14]}$ Fenton reaction convert $\mathrm{O}_{2}{ }^{-}$and $\mathrm{H}_{2} \mathrm{O}_{2}$ to the most reactive $\bullet \mathrm{OH}$ and cause great damage to biomolecules, even death. The previous research proved that under the stress, the flavonoids contribute more significantly than the antioxidases. ${ }^{[15]}$ In our study, the PALs were highly expressed, the antioxidases slightly increased, flavonoids must be do excellent service in eliminating ROS. 


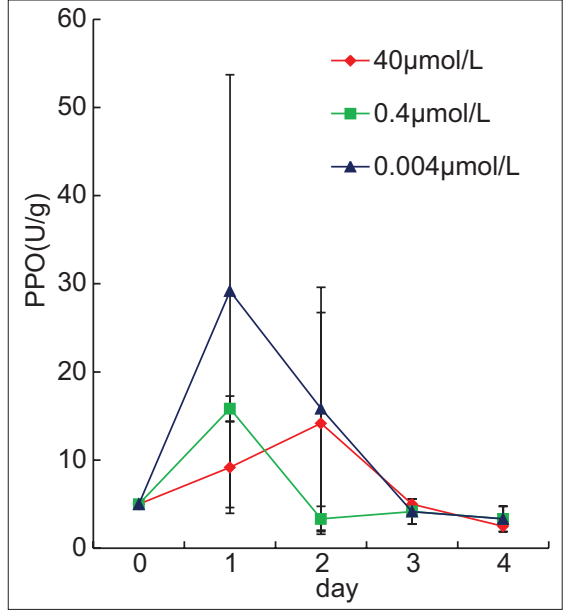

Figure 5: Activities of polyphenol oxidase in the roots of Scutellaria baicalensis. Initially, polyphenol oxidase activities were raised, then gradually decreased. It accords with that of aglucon

The ROS generated by $\mathrm{Na}_{2} \mathrm{~S}_{2} \mathrm{O}_{4}$ have a capacity for the modification of secondary metabolism. The baicalin and wogonoside change slightly, but the baicalein and wogonin had great changes, roughly doubled. The fact that the differences exist seems to be due to three reasons. First, the bioavailability is a crucial factor for better effect. ${ }^{[16]}$ Both baicalein and wogonin are aglucon, with the greatest fat-solubility. The fat-soluble analog usually was the greatest effective, it may be related to fact that the fat-solubility can diffuse through aquaporins in the membranes and over larger distances within the cell. ${ }^{[17]}$ Second, the baicalein and wogonin possess two hydroxy groups, with more effective than its counterparts. It has proved that the absorptivity of baicalein is more than 7 times that of the baicalin, the antibacterial activity is $2 \sim 5$ times as that of the other flavonoids, the activity inhibiting interleukin- $1 \beta$ converting enzyme is $1 \sim 3$ times as the other related substances. ${ }^{[18]}$ The baicalein, not the other flavone, has been shown to be high level in famous region drug (mean high-quality medicinal materials), even as one of the useful indicators to adopt for the quality control of $S$. baicalensis. ${ }^{[12,19]}$ Which reminding us that baicalein plays a crucial role in antioxidation. ${ }^{[20]}$ Third, less aglucon and more glycoside present in cells of S. baicalensis, once the environmental stresses befall, the conversion of less active glycoside into more active aglucon immediately ensue. Moreover, the biosynthesis of aglucon precedes glycoside, it is necessary to keep aglucon high level under stress from $\mathrm{Na}_{2} \mathrm{~S}_{2} \mathrm{O}_{4}$. In a natural state, more flavonoid glycosides and less aglycones exist in normal cell, even considered baicalin as a state baicalein stored. ${ }^{[21]}$ Therefore, aglycones are the most major physiological parameters to assess the quality of radix scutellariae. With increased antioxidase activities and flavonoids, redundant ROS were gradually eliminated, followed by a surplus of flavonoids which, in turn, would make ROS keep too low and disrupt the cellular homeostasis in such a condition. Along with increased flavonoids, the activities of PPO also were gradually raised to eliminate redundant baicalein and wogonin [Figure 5], Therefore, the baicalein and wogonin begin to decline after the $1^{\text {st }}$ day.

\section{CONCLUSION}

ROS are produced in plants under disadvantaged conditions. $\mathrm{Na}_{2} \mathrm{~S}_{2} \mathrm{O}_{4}$ can act as an unfavorable factor to generate $\mathrm{O}_{2}{ }^{-}$, which is then converted into $\mathrm{H}_{2} \mathrm{O}_{2}, \bullet \mathrm{OH}$, and other ROS. Based on this theory, organisms treated with $\mathrm{Na}_{2} \mathrm{~S}_{2} \mathrm{O}_{4}$ can be used as basic models for studying environment stress. Furthermore, $\mathrm{Na}_{2} \mathrm{~S}_{2} \mathrm{O}_{4}$ has strong reducing ability, easily transforms into noxious $\mathrm{NaHSO}_{4}$, and it is widely applied as the dechlorination agents in tap water, beer bottle disinfectant, bleaching agent, and food leavening agent. The application of $\mathrm{Na}_{2} \mathrm{~S}_{2} \mathrm{O}_{4}$ to $\mathrm{S}$. baicalensis is also reasonable and practicable to enhance the quality of radix scutellariae.

\section{Acknowledgments}

This project was supported by the National Nature Science Foundation of China (No. 81573523).

\section{Financial support and sponsorship}

Nil.

\section{Conflicts of interest}

There are no conflicts of interest.

\section{REFERENCES}

1. Zhao $Q$, Zhang $Y$, Wang G, Hill L, Weng JK, Chen $X Y$, et al. A specialized flavone biosynthetic pathway has evolved in the medicinal plant, Scutellaria baicalensis. Sci Adv 2016;2:e1501780.

2. Zhang YG, Han $M$, Jiang $X$, Zhao SN, Yang LM. Effect of environmental factors on photosynthetic physiology and flavonoid constituent of Scutellaria baicalensis. Zhongguo Zhong Yao Za Zhi 2014;39:1761-6.

3. Natesan G, John RJ, Ganesan S, Subramanian K. The comparative studies of the phytochemical levels and the in vitro antioxidant activity of Tridax procumbens L. from different habitats. Free Radic Antioxid 2016;7:50-6.

4. Ren DQ, Zhou RH. Good agricultural practice (GAP) implementation guide for Chinese crude drug. Beijing: China Agricultural Press; 2003. p. 83-6.

5. Zhang B, Peng Y, Zhang Z, Liu H, Qi Y, Liu S, et al. GAP production of TCM herbs in China. Planta Med 2010;76:1948-55.

6. Yuan Y, Liu Y, Wu C, Chen S, Wang Z, Yang Z, et al. Water deficit affected flavonoid accumulation by regulating hormone metabolism in Scutellaria baicalensis Georgi roots. PLoS One 2012; 7:e42946.

7. Sharma P, Jha AB, Dubey RS, Pessarakli M. Reactive oxygen species, oxidative damage, and antioxidative defense mechanism in plants under stressful conditions. J Bot 2012;2012:1-26.

8. Weng YK, Huang S, Weng NY. Superoxide radicals could be generated with sodium hydrosulfite. Prog Biochem Biophys 1989;16:209.

9. Giannopolitis CN, Ries SK. Superoxide dismutases: II. Purification and quantitative relationship with water-soluble protein in seedlings. Plant Physiol 1977; 59:315-8.

10. Zeng SX, Wang YR, Liu HX. Some enzymatic reactions related to chlorophyll degradation in cucumber cotyledons under chilling in the light. Acta Phytophysiol Sin 1991;17:177-82.

11. Willekens $H$, Chamnongpol S, Davey M, Schraudner M, 
Langebartels C, Van Montagu M, et al. Catalase is a sink for $\mathrm{H} 2 \mathrm{O} 2$ and is indispensable for stress defence in C3 plants. EMBO J 1997;16:4806-16.

12. Dietz KJ, Turkan I, Krieger-Liszkay A. Redox-and reactive oxygen species-dependent signaling into and out of the photosynthesizing chloroplast. Plant Physiol 2016;171:1541-50.

13. Boyle SP, Doolan PJ, Andrews CE, Reid RG. Evaluation of quality control strategies in Scutellaria herbal medicines. J Pharm Biomed Anal 2011;54:951-7.

14. Perez CA, Wei Y, Guo M. Iron-binding and anti-Fenton properties of baicalein and baicalin. J Inorg Biochem 2009;103:326-32.

15. Qi S, Wu-Lin C, Hua J, Ai-Hua Z, Xiang-Cai M. H2O2 improves quality of radix scutellariae through anti-oxidant effect. Pharmacogn Mag 2016;12:84-90.

16. Madan JR, Pawar KT, Dua K. Solubility enhancement studies on lurasidone hydrochloride using mixed hydrotropy. Int J Pharm Investig 2015;5:114-20.
17. Hong C, Dang Y, Lin G, Yao Y, Li G, Ji G, et al. Effects of stabilizing agents on the development of myricetin nanosuspension and its characterization: an in vitro and in vivo evaluation. Int J Pharm 2014;477:251-60.

18. Liu TM, Jiang XH. Studies on the absorption kinetics of baicalin and baicalein in rats' stomachs and intestines. Zhongguo Zhong Yao Za Zhi 2006;31:999-1001.

19. Yang LX, Liu D, Feng XF, Cui SL, Yang JY, Tang XJ, et al Determination of flavone for Scutellaria baicalensis from different areas by HPLC. Zhongguo Zhong Yao Za Zhi 2002;27:166-70.

20. Hirunuma M, Shoyama Y, Sasaki K, Sakamoto S, Taura F, Shoyama Y, et al. Flavone-catalyzed apoptosis in Scutellaria baicalensis. Phytochemistry 2011;72:752-60.

21. Hirotani M, Kuroda R, Suzuki H, Yoshikawa T. Cloning and expression of UDP-glucose: Flavonoid 7-O-glucosyltransferase from hairy root cultures of Scutellaria baicalensis. Planta 2000;210:1006-13 